\title{
Labor Market Concentration Does Not Explain the Falling Labor Share*
}

\author{
Ben Lipsius \\ University of Michigan \\ Job Market Paper
}

The latest version can be downloaded here

First Version: August, 2018

This Version: November, 2018

\begin{abstract}
Using U.S. administrative data, this paper shows that the employment-weighted average labor market concentration has been declining since 1980 - the opposite of the change needed to explain the falling labor share. The relationship between wages and labor market concentration has also weakened (become less negative) over that time. Together, these results make labor market concentration an implausible driver of the falling labor share despite a strong, negative relationship between labor market concentration and wages.
\end{abstract}

DISCLAIMER: "Any opinions and conclusions expressed herein are those of the author(s) and do not necessarily represent the views of the U.S. Census Bureau. All results have been reviewed to ensure that no confidential information is disclosed."

\footnotetext{
${ }^{*}$ My thanks to my committee: Matthew Shapiro, Martin Schmalz, Charlie Brown and Kyle Handley. I am also grateful to everyone who has provided comments, guidance, and support including, but not limited to, Steve Hamilton, Jay Kahn, Laurien Gilbert, Andrew Usher, Clint Carter, Malcolm Wardlaw, Javier Miranda and seminar participants at University of Michigan and at the U.S. Census Bureau

Email: blipsius@umich.edu. Website: benlipsius.com.
} 


\section{Introduction}

Economists and policy makers are worried about the falling labor share and stagnating wages. In his address at the 2018 annual Fed conference in Jackson Hole, WY, Alan Krueger (Krueger, 2018) cites recent papers showing that labor market concentration is negatively correlated with wages. The authors of these papers extend their arguments to connect labor market concentration and the declining labor share. The non-representative nature of the data used by these studies, however, raises doubts about their conclusions concerning the contribution of labor-market concentration to changes in the labor share.

This paper examines the connection between the labor share and labor market concentration using U.S. administrative data covering all urban, private, non-farm employment, from 1980 to 2012. I find that labor market concentration is an implausible driver of the falling labor share. The employment-weighted average labor market concentration has been declining since 1980 - the opposite of the change needed to explain the change in the labor share (or stagnant wages). Not only has the employment-weighted average labor market concentration declined, but the relationship between labor market concentration and wages has also weakened over the period of this study. Taken together, these results show that changes in labor market concentration has not caused the falling labor share.

In order to connect labor market concentration and the labor share, I first develop a model connecting a labor market's concentration to its wages. In this labor market, firms decide how many people to employ knowing how their employment decision will affect wages and knowing other firms' desired hiring. The model implies a negative relationship between a labor market's concentration and its wages. I then test and confirm this model-implied relationship. Benmelech et al. (2018) and Azar et al. (2017), the papers cited by Kreuger in his address about recent labor market trends, also find that labor market concentration is negatively related to wages.

After confirming the relationship between labor market concentration and wages, I relate wages to the labor share. The labor share is the percent of aggregate output that goes to compensating labor and therefore is based, in part, on aggregate wages. Each labor market's wages need to be employment-weighted to properly aggregate them into average wages. By using the model- 
derived relationship between labor market wages and labor market concentration, I show that the employment-weighted average labor market concentration is the relevant measure to link labor market concentration and aggregate wages, and, therefore, the labor share. The time series of the employment-weighted average concentrations, however, goes in the opposite direction of that needed to explain the falling labor share. This finding is in line with findings in Rossi-Hansberg et al. (2018) and Rinz (2018).

While the employment-weighted average labor market concentration has been declining since 1980, if the relationship between labor market concentration and wages has strengthened (become more negative), labor market concentration could still explain the declining labor share. To examine this possibility, I divide the sample into subsamples and re-estimate the relationship between wages and concentration in each. I find that the relationship between wages and labor market concentration has weakened (become less negative) over the period of study. Because both the employment-weighted average labor market concentration has fallen and the relationship between wages and labor market concentration has weakened, labor market concentration does not explain the falling labor share.

As a final extension, I incorporate product market power into my model of labor markets. Product market power combined with labor market power incentivizes firms to further restrict labor (and therefore wages) to earn profits in both the labor and the product markets. This relationshipship exists empirically as well: labor markets that produce goods for output markets with market power have a stronger (more negative) relationship between labor market concentration and wages than do labor markets that produce goods for output markets without market power. I thus complement the expanding literature on increasing product market concentration and its connection with the falling labor share. While labor market concentration does not explain the falling labor share, if increasing product market concentration increases product market power, then increasing product market power could help explain the falling labor share.

Labor market concentration's decline concurrent with product market concentration's increase, and the link between increased product market concentration and lower wages argue for the continued use of the so-called consumer welfare standard of anti-trust regulation. Adopting a regulatory standard based on labor market concentration instead of product market concentration, such as 
that suggested in Naidu et al. (2018) and Marinescu and Hovenkamp (2018), would solve a problem (increasing labor market concentration) that does not exist in the data. The employment-weighted average labor market concentration is the amount of labor market concentration faced by the average U.S. worker. The time series of the employment-weighted average concentrations shows that labor market concentration is a decreasing problem for this average worker. Additionally, it could block productivity-enhancing mergers because of increased concentration in relatively small labor markets, affecting relatively few workers, and in essence, prioritize these small negative effects over national benefits.

The paper proceeds as follows: Section 2 describes this paper's relationship to other papers in the falling labor share and in the concentration and wages literatures; Section 3 develops the model relating wages to labor market concentration; Section 4 describes the data; Section 5 presents the findings of the paper; Section 6 presents results on sub-periods and extends the model to include product market power; and Section 7 concludes.

\section{Concentration and Labor Share: Literature Review}

This paper is most closely related to Benmelech et al. (2018), Azar et al. (2017), Azar et al. (2018), and Rinz (2018) but is significantly different from each in important ways. It uses more industries than Benmelech et al. (2018) and so provides insight into the macro-economy as opposed to a single industry; it uses a longer time series than either Azar et al. (2017) or Azar et al. (2018) and uses actual employment data rather than advertised jobs and so provides insight into the trend of employment concentration; and it answers a different question than Rinz (2018) though that paper employs similar techniques and data sets.

Benmelech et al. (2018) focuses its analysis solely on manufacturing while this paper uses all private, non-farm industries. Because there are qualitative differences between manufacturing's average and employment-weighted average labor market concentration and the aggregate's, they mistakenly conclude that labor market concentration is an increasing problem. This qualitative difference can be understood in terms of manufacturing's declining role in U.S. employment: according to the BLS, the percentage of employment engaged in manufacturing dropped from about 
$22 \%$ in 1980 to just over $10 \%$ in 2012 .

Both Azar et al. (2017) and Azar et al. (2018) use online job posting data and so are limited in terms of the accuracy and comprehensiveness of their sources. Azar et al. (2017) uses CareerBuilder.com data for 2010-2012. Beyond its inability to look at trends, there are questions about the representativeness of these data and how to interpret them. Not every job is posted on Careerbuilder.com- Azar et al. (2017) only examine jobs in 26 SOC occupation codes-and only about $20 \%$ of postings contain wage information, raising concerns about selection into posting on the website and, conditional on posting on the website, selection into posting a wage. ${ }^{1}$ Azar et al. (2018) uses a more comprehensive online job postings data from Burning Glass Technologies (BGT), but limit themselves to a single year-2016. Within these data, $40 \%$ of job postings have missing employer information. ${ }^{2}$ By using administrative data from 1980-2012, this paper is able to examine the trends in labor market concentration. Additionally, these data cover all private, non-farm employment and realized wages. This coverage allows me to calculate concentration using actual employment, independent of firm advertising behavior and examine the correlation of wages with the labor market concentration instead of relying on advertised wages in a selected sample of two job boards.

Rinz (2018) uses the same data as this paper and finds the same dynamics: local labor market concentration has been declining while national concentration has been increasing. He uses these facts to examine earnings outcomes of different types of workers and earnings mobility. I use the relationship between labor market concentration and wages to examine changes in the labor share.

Rossi-Hansberg et al. (2018) uses NETS (National Establishment Time Series) to calculate national and local sales concentrations from 1990 to 2014. NETS provides microlevel data on US establishments. While NETS is closely related to the data used in this study, Haltiwanger et al. (2013) and Barnatchez et al. (2017) question its coverage. This paper calculates concentration in

\footnotetext{
${ }^{1}$ This paper additionally calculates concentration as "the share of vacancies of all the firms that post vacancies in that market." Without knowing the underlying firm behavior-how is the share of job postings within CareerBuilder.com correlated with the share of employment in a given labor market?-it is impossible to interpret the concentrations they calculate. Finally, because there is no measure of labor market employment, the average concentration calculated in this study gives equal weight to small labor markets and large labor markets. The simple average presented, therefore, tells us nothing about the concentration facing average workers.

${ }^{2}$ It is unclear how many observations have wage data. The qualifications about differences in firm behavior and the relationship between actual wages and advertised wages also apply.
} 
employment instead of sales and uses the relationship between concentration and wages to examine how labor market concentration is related to the labor share. Despite these differences in data source, the overall trends in Rossi-Hansberg et al. (2018) are consistent with both Rinz (2018) and this paper: though nationally calculated concentration has increased over the period of study, local trends move in the opposite direction.

In addition to these recent papers, there is an older literature relating labor market concentration to wages that produced mixed results. Boal and Ransom (1997) survey the state of the literature until 1997 and point out that in some studies labor market concentration is highly correlated with wages while in others the correlation disappears. These studies, however, cover relatively few labor markets-the papers they cite vary from a few hundred to a few thousand labor marketsand mostly focus on either nurses or teachers. Additionally, most of these are cross-sectional studies. This paper uses a panel data set with approximately 6.9 million different markets. The panel allows the relationship between labor market concentration and wages to be identified from within-labor market variation instead of relying on cross-sectional variation-a feature driven by the theory developed in this paper. Using only the within-labor market variation also mitigates concerns that the correlation between labor market concentration and wages reflects differences between labor markets i.e. low-productivity labor markets have low wages and few firms therefore creating a correlation between the labor market concentration and wages.

Finally, this paper contributes to a growing literature connecting the falling labor share to concentrating markets. Autor et al. (2017) and Kehrig and Vincent (2017) argue that concentrating output markets has pushed production into lower labor share firms, thereby depressing the labor share. Meanwhile Barkai (2016) and De Loecker and Eeckhout (2017) argue that concentrating output markets has increased mark ups and the additional value generated has gone into profits, thereby increasing the capital share to the detriment of the labor share. Instead of examining product market concentration, this paper focuses on labor market concentration and shows that while product markets have been getting more concentrated, labor markets have been getting less concentrated. This finding is consistent with national chains' replacing local firms. If national chains have a lower labor share than local firms, then national chains' replacing local stores would drive down the labor share as described in Autor et al. (2017) and Kehrig and Vincent (2017). 
This paper also provides evidence that increasing product market power can decrease wages. If increased national concentration has created more product market power, then product market power decreasing the labor share would be consistent with Barkai (2016) and De Loecker and Eeckhout (2017). This paper does not provide evidence for or against any of these studies of national concentration, but should be considered complementary to them.

\section{Linking Labor Market Concentration and Wages}

In this section I lay out a simple model of labor markets in which the market's wage depends on its level of concentration. I then discuss the basis of the model's assumptions and connect the model to the parts of this study's empirical specification regarding the choice of concentration measure and the variation used to estimate the relationship between labor market concentration and wages. Later in Section 6.2, the model is extended to include product market power along with labor market concentration.

\subsection{Model}

There are $N$ firms in the labor market, indexed $i=1, \ldots, N$. Firms produce output with a linear production technology in labor. Each firm receives a productivity draw, $a_{i}$ around a common component, $\bar{A}$. The productivity draws across firms are mean zero, i.i.d., and $a_{i} \in[-\bar{a}, \bar{a}]$ with $\bar{a}<\bar{A}$ so that all firms have positive productivity. Firm $i$ 's productivity is thus $A_{i}=\bar{A}+a_{i}$.

Labor supply is given by a constant-elasticity labor supply function common to all firms. Let

$l_{i}$ be firm $i$ 's employment and let $L=\sum_{i=1}^{N} l_{i}$ be the total employment in the labor market. Wages are set according to

$$
w(L)=\gamma L^{\varepsilon^{-1}}
$$

where $w(L)$ is the wage and $\varepsilon$ is the elasticity of labor.

Each firm chooses its employment to maximize profits knowing the other firms' desired hiring 
and the labor supply curve,

$$
\max _{l_{i}} A_{i} l_{i}-w(L) l_{i}
$$

This maximization leads to each firm's first order condition

$$
A_{i}-w(L)=w^{\prime}(L) l_{i}
$$

By substituting the labor supply function, Equation 3 can be rewritten as

$$
\frac{A_{i}-w(L)}{w(L)}=\frac{A_{i}}{w(L)}-1=\varepsilon^{-1} s_{i}
$$

where $s_{i}=\frac{l_{i}}{L}$ is firm $i$ 's share of employment in the labor market. Multiplying by $s_{i}$, further rearranging, and summing across all firms leads to

$$
\frac{1}{w(L)}\left(\frac{\sum_{i=1}^{N} A_{i} l_{i}}{L}\right)=\left(1+\varepsilon^{-1} \sum_{i=1}^{N} s_{i}^{2}\right)
$$

$\sum_{i=1}^{N} s_{i}^{2}$ is the Herfindahl-Hirschman index (HHI), a commonly used measure of market concentration. ${ }^{3}$ Taking logs and rearranging finally yields

$$
\log (w)=\log (\bar{A})+\log \left(\frac{\bar{A} L+\sum_{i=1}^{N} a_{i} l_{i}}{\bar{A} L}\right)-\log \left(1+\varepsilon^{-1} \mathrm{HHI}\right)
$$

the relationship between the wages and the labor market concentration.

Additionally, using equations 1 and 3 to solve for total labor market employment, $L$, yields

$$
L=\left[\frac{n \bar{A}}{\gamma\left(\varepsilon^{-1}-n\right)}\right]^{\varepsilon}
$$

In this expression, the total size of the labor market is directly related to an invertible function of the total productivity in the market. This one-to-one relationship between market size and productivity will be useful later in the paper when proxying for potentially omitted variables.

\footnotetext{
${ }^{3}$ The HHI ranges from 0 to 1 with 0 being a perfectly competitive market and 1 being a single firm in the market.
} 


\subsection{Discussion}

The preceding model establishes a direct link between wages and labor market concentration, but other features of the model are worth noting. This section will discuss these features and link the model to the empirical specification.

The firms' productivities are made up of a common component and an idiosyncratic component. The common component groups the firms' productivities while the idiosyncratic component creates a productivity distribution within the labor market. This specification is meant to match the firm sorting found in the economic geography literature: firms choose locations to be in close proximity to other firms of a similar productivity level. This phenomenon is economically important. Gaubert (2018) finds that nearly half the productivity advantage enjoyed by cities in France is due to firm sorting. The common component also helps determine the variation needed to estimate the model. $\log (\bar{A})$ in Equation 6 translates into a labor market fixed effect in the empirical specification. This fixed effect means the relationship between wages and labor market concentration is identified using the within-market variation. Section 5.1 will discuss in more detail the advantages of this empirical strategy.

Equation 4 shows that a firm's profits are related to the labor supply elasticity and to the firm's relative size in the market. The left-hand side of the equation is the mark up over wages, the only cost in the model. In this setting, as a firm becomes more productive, all else being equal, it will earn a higher mark up and employ a larger share of the labor market. The right-hand side of the equation is the product of the labor supply elasticity and the firm's share of the labor market. This expression determines how much of the additional productivity is captured by workers as a firm's share of the labor market, and therefore its productivity, increases. Weighting Equation 4 by the share of labor market employment and summing across all the firms leads to Equation 5. Here, the total per-employee profit of the labor market is related to the total labor market concentration as measured by the HHI.

Finally, Equation 6 shows that wages are related to the labor market's total productivity along with the market fixed effect and concentration. Unfortunately, while the data set used for the main analysis contains firm employment and wage data, it has no information about productivity. Equa- 
tion 7 relates a product market's productivity directly to the size of the total labor market. This relationship provides a natural proxy for the potentially omitted variables. Section 5.1 discusses the potential bias from this omitted variable more thoroughly.

\section{Data}

\subsection{The LBD}

The main source of data for this study is the Census Bureau's Longitudinal Business Database (LBD). The LBD covers the near-universe of non-farm, private establishments with employees. For each establishment, it provides the total number of employees and the total pay of the establishment as of March 13 of the given year. Hence, only establishment-average wages can be calculated from the data. Longitudinal links are created using a variety of methods. Jarmin and Miranda (2002) provide full details of the construction of the LBD.

Because this study defines labor markets to exclude rural areas, it does not use the full LBD. Figure 1 shows the total jobs covered in each year, from 61 million jobs in 1980 to 104 million jobs in 2012. The full sample has about 850 cities and about 600 industries. It is important to note that not every city will have every industry code and not every year has 850 different cities.

Panel (a) of Table 1 gives summary stats for the full sample. There are 6.94 million observations in the complete sample. Each observation is a labor market. The average HHI over the entire

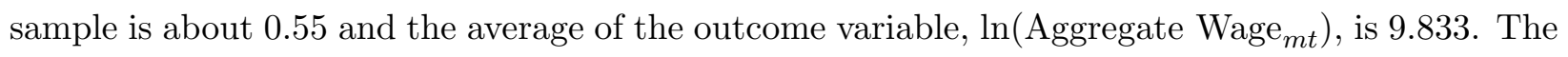
average $\ln$ (employment) is 3.652 which corresponds to about 37 employees in each labor market, and there are an average of 19 firms in each labor market. Finally, Annual Markets is the average number of markets in each year of the sample period. Standard deviations are below the averages in parentheses.

\subsection{Definitions}

The first step in examining labor markets is defining labor markets. This paper defines labor markets as industries within an urban area. Based on this definition, firms operating multiple 
establishments within a labor market are counted as one and firms operating in multiple industries are counted separately. Undergirding these decisions is the premise that firms within a labor market compete with each other for labor. The rest of the section lays out the details around these choices.

This paper uses 5-digit NAICS industrial codes for its industrial classification. The NAICS industrial codes are applied to establishments based on the economic activity that the greatest number of employees are engaged in at that establishment. This classification philosophy constrasts with the older SIC classifications that assign industry codes based on what the establishments' parent company does. By way of example, employees at a warehouse whose parent company is in manufactoring would be correctly identified as working in a warehouse under NAICS codes but would be wrongly classified as manufacturing workers under the SIC coding. In fact, Fort and Klimek (2016) show that using SIC codes misclassifies a significant number of workers. The Census Bureau provides the establishment level industry identification developed in Fort and Klimek (2016) to researchers using the LBD.

The difference between NAICS and SIC codes is important for labor markets. Using classifications more closely aligned with the economic activities at the establishments allows more-similar establishments to be grouped more easily. Establishments engaged in the same economic activity presumably compete for the same employees and so are in the same labor market. This definition contrasts with studies that use SIC codes. Using SIC codes, or assigning a single NAICS code to all of a firm's establishments, is appropriate in studies of product market concentration because they are measuring the total labor that goes into making the firm's final output. Studies of labor markets, like this one, however, need to differentiate the types of labor that go into production. This study accomplishes this by using establishment level NAICS codes then aggregating to firm level employment.

The second component of labor market definitions is geographic. Firms in economically integrated areas presumably compete for the same workers while firms in areas that are not economically integrated do not. Urban areas (CBAs, CBSAs, and Micropolitan Areas, the successors to MSAs, referred to as cities from now on) make the most natural geographic definition for a labor market because they are local definitions created by the OMB based on the economic integration of cities and their surrounding areas. Recent evidence suggests this generalization is a good approxima- 
tion of labor markets. Within the US, internal migration has been declining (Molloy et al., 2014; Partridge et al., 2012). Additionally, Manning and Petrongolo (2017) and Marinescu and Rathelot (2016) provide evidence of the local nature of job search among potential employees. Finally, moving is expensive. Bartik (2017) finds the adjustment costs to moving (including non-pecuniary costs) are over $\$ 100,000$.

Once the local nature of labor markets is accepted, however, there are still several ways to define them: cities, commuting zone, or county definitions could all be called "local." On closer analysis, however, only the urban area definition are appropriate for a study like this one. Commuting zones are designed by the USDA to incorporate rural areas into the closest city as measured by economic integration. The city definitions, however, are already based on economic integration. Though the rural areas might be most integrated into the particular city in their commuting zone, they are not integrated enough to be included in the initial urban area definitions. That is, they are not integrated into their assigned cities and are most useful in studies that need to cover the entire U.S. land mass. Foote et al. (2017) shows using this over-broad definition of local labor markets can affect empirical estimates. While commuting zones are too large, counties are too small. Counties are political units. They are not based on the economic realities of the area and many cities are made up of multiple counties. Using a county-based definition of labor markets suggests that firms in different counties don't compete with each other for labor. For example each of New York City's five boroughs is its own county. County-based labor market definitions imply restaurants in Brooklyn and Manhattan do not compete for employees. Because cities' definitions are based on economic integration instead of political boundaries or geographic proximity and they allow competition within those areas of integration, they are the most natural choice for a study of labor markets. Cities themselves are not static. The OMB periodically updates its definitions of cities to reflect which areas are economically integrated in a particular year. This study uses these changing MSA definitions because they are the best measure of what the labor market was like in that particular year. Concerns that these changing geographical definitions' driving later results are addressed in Section 5.2.

Having a definition for labor markets allows me to define the firms operating in those markets. The Census Bureau creates a unique firm identifier that connects all of a firm's establishments 
(for those firms with multiple establishments) and provides enough geographic data to locate each establishment within an urban area. Many firm identifiers are linked to establishments in multiple labor markets, to multiple establishments in the same labor market, or both. For the purposes of this study, a firm is a firm identifier and labor market combination. This firm definition allows firms to operate in multiple labor markets within the same city and to compete for various types of workers. Firms (firm identifier by labor market) that operate multiple establishments within the same labor market are considered as a unit so the employment at these multiple establishments is aggregated into one firm to calculate concentration. Underlying this aggregation are 2 assumptions: first, establishments do not make hiring and pay decisions independently of each other and second, establishments owned by the same firm do not compete with each other for employees. These assumptions are in line with the discussion of wage decision making in Bloom et al. (2015) where they echo the Bureau of Labor Statistics' assumption that, "the firm level is more consistent with the role of corporations as the economic decision makers than each individual establishment."

Using these definitions of labor markets and firms, I can calculate labor market concentration. This study's model suggests (Section 3) using the HHI as its measure of labor market concentration. In this context, the HHI is the sum of the squared shares of the labor market each firm hires. That is, for a market with $N$ firms,

$$
\mathrm{HHI}=\sum_{i=1}^{N} s_{i}^{2}
$$

where $s_{i}=\frac{l_{i, M}}{L_{M}}$ is the fraction of employment employed at firm $i$ in labor market $M$ and $L_{M}=$ $\sum_{i}^{N} l_{i, M}$ is the total employment in labor market $M$.

In addition to a measure of concentration, this study needs a measure of wages within the labor market. The theory presented earlier does not allow for wages to differ across firms. This assumption contrasts with an extensive literature on wage dispersion (see Mortensen (2005) for a summary of the literature to 2005). To best mimic a common component of wages that is affected by the labor market's concentration, I calculate the average wage as the employment-weighted 
average wage of the firms

$$
\text { wage }=\sum_{i=1}^{N} \frac{l_{i}}{L} \frac{p_{i}}{l_{i}}
$$

where $p_{i}$ is the total pay at firm $i$. This value is alternatively calculated as the total pay within a labor market over the total labor in that market. I refer to this as the aggregate wage to distinguish it from the average wage at a particular firm $\frac{p_{i}}{l_{i}}$. This distinction is important for interpreting results later in Section 5.1.

\section{Results}

This section presents analysis using the data described in Section 4.1 and the definitions described in Section 4.2. The first section describes the regression analysis and shows that the relationship between labor market concentration and wages is the same in these data as suggested by the model in Section 3. The second section connects labor market concentration to the labor share and shows that it is an implausible driver of the decline in the labor share.

\subsection{The Relationship between Wages and Concentration}

\subsubsection{Methodology}

The theory in Section 3 relates the log of wages to a fixed effect, a measure of market-level productivity, and a non-linear function of the labor market's concentration. In keeping with that theory, I use a market-level regression specification for my analysis:

$$
\log \left(w_{m t}\right)=\alpha+\alpha_{t}+\alpha_{m}+\beta_{1} \mathrm{HHI}_{m t}+\beta_{2} \mathrm{HHI}_{m t}^{2}+\beta_{3} \Psi_{m t}+\varepsilon_{m t}
$$

where $w_{m t}$ is the aggregate wage, $\alpha_{t}$ is a time fixed effect so the results can be interpreted in real

terms, $\alpha_{m}$ is a labor market fixed effect, $\mathrm{HHI}_{m t}^{2}$ is the square of the labor market's concentration measure to control for the nonlinearity of the $\log ()$ function in Equation 6 and $\Psi_{m t}$ are labor market level controls. As controls I use the log of total labor market employment, $\log \left(e m p_{m t}\right)$ and 
the number of firms in the market, $N$. I cluster standard errors at the labor market level.

The controls and fixed effects alleviate some possible concerns with this regression analysis. The first possible concern is the omitted productivity term from Equation 6 . The equation shows that labor market productivity is positively correlated with the wages. If the labor market productivity is negatively correlated with the concentration (more productive markets have lower concentration levels) this will introduce a negative bias into the estimate. If, on the other hand, labor market productivity is positively correlated with the concentration, omitting the variable will introduce a positive bias in the estimate. I use the $\log$ of the total labor market employment, $\ln \left(e m p_{m t}\right)$, to proxy for market level productivity because the size of the labor market is a direct result of the market's aggregate productivity in the model as shown in Equation 7.

In addition to concerns about the omitted productivity variable, there are concerns that the negative correlation between wages and the labor market concentration is driven by some third phenomenon. The two most obvious possible confounders are search frictions and between-labor market productivity. If search frictions are negatively correlated with wages but positively correlated with the concentration of the labor market (if it is harder to find a job in a more concentrated labor market) then the results of regressing wages on concentration could reflect this relationship. I use the number of firms in the market, $N$, to control for this possibility, assuming that search frictions are a function of $N$.

Cross-sectional correlation between productivity and wages could also confound estimates of the relationship between labor market concentration and wages. However, because of the panel structure of these data, I am able to include the labor market fixed effect corresponding to $\log (\bar{A})$ in Equation 6. This fixed effect eliminates all the between-group variation from the estimate, i.e. the coefficients of interest, $\beta_{\mathrm{HHI}}$ and $\beta_{\mathrm{HHI}^{2}}$, are estimated using only the time series variation within a labor market. This estimation strategy helps alleviate some of the concerns that the relationship between the wage and the level of concentration reflects the relationship between area productivity and wages. One possible concern with this strategy, however, is whether there is enough variation in the time series of the HHI within labor markets to make accurate estimates. Because the average standard deviation of the HHI within a market is 0.119 , this concern is unwarranted. 


\subsubsection{Results}

Table 3 presents the regression results from estimating Equation 10 with various combinations of fixed effects and controls. All of the relationships presented in the table are significant to the $1 \%$ level. The first specification uses time and labor market fixed effects and does not include the market-level control variables. These results are in Column (1). The marginal effect at the mean is -0.2434 . Going from the mean concentration level (.5499) to 1 standard deviation (.3517) above the mean, all else remaining equal, is associated with a decrease in log(wages) of -.0907 or about $-8.6 \%$. The specification in Column (2) replaces the time fixed effect with time-by-city and time-by-industry fixed effects. Instead of controlling just for national trends, these additional fixed effects control for city trends and for national-industry trends, respectively. Adding these fixed effects attenuates the effect at the mean; it drops from -0.2434 to -0.1867 . In this specification, going from the mean concentration to one standard deviation above the mean, all else remaining equal, is associated with a decrease in $\log$ (wages) of .0768 which corresponds to a $7.7 \%$ decrease in wages.

Columns (3) and (4) display the results of adding controls to the fixed effect structures. Column (3) only has time and market fixed effects while column (4) has market fixed effects and time-byindustry and time-by-city fixed effects. Adding the additional controls attenuates the relationship between concentration and wages slightly: the marginal effect at the mean is about .017 smaller in Column (3) than in Column (1) and is about .02 smaller in Column (4) than in Column (2). This attenuation is in keeping with market employment's proxying for market productivity and correcting the negative bias from the omitted variable. The positive coefficients on $\ln (\mathrm{emp})$ also support this interpretation. The model suggests employees in more productive markets should make more money. Interestingly, the coefficients on $N$ are negative. Holding constant the labor market's concentration and the overall employment of the market while increasing the number of firms in the market must decrease the average firm size. Lower wages are therefore correlated with smaller firms. Thus, these negative coefficients are in line with the well-known firm-size effect described in Oi and Idson (1999).

Because I am using a second order Taylor series expansion for $-\log \left(1+\varepsilon^{-1} \mathrm{HHI}\right)$, I can use 
$\beta_{\mathrm{HHI}}$ and $\beta_{\mathrm{HHI}^{2}}$ to obtain estimates of $\varepsilon^{-1}$, the inverse elasticity of labor. The second order Taylor series expansion for this function is

$$
-\log \left(1+\varepsilon^{-1} \mathrm{HHI}\right) \approx \gamma-\frac{\varepsilon^{-1}}{1+\varepsilon^{-1} \mathrm{H} \overline{\mathrm{HI}}}(\mathrm{HHI}-\mathrm{H} \overline{\mathrm{HI}})+\frac{\varepsilon^{-2}}{2\left(1+\varepsilon^{-1} \mathrm{H} \overline{\mathrm{HI}}\right)^{2}}(\mathrm{HHI}-\mathrm{H} \overline{\mathrm{HI}})^{2},
$$

where $\gamma$ is a constant and $\mathrm{HHI}$ is the point around which the function is expanded. Collecting terms related to the regression specification yields

$$
\begin{aligned}
\beta_{\mathrm{HHI}} & =-\left[\frac{\varepsilon^{-1}}{\left(1+\varepsilon^{-1} \mathrm{H} \overline{\mathrm{HI}}\right)}+\frac{\varepsilon^{-2} \mathrm{H} \overline{\mathrm{HI}}}{\left(1+\varepsilon^{-1} \mathrm{H} \overline{\mathrm{HI}}\right)^{2}}\right] \\
\beta_{\mathrm{HHI}^{2}} & =\frac{-\varepsilon^{-2}}{2\left(1+\varepsilon^{-1} \mathrm{H} \overline{\mathrm{HI}}\right)^{2}} .
\end{aligned}
$$

Solving this system of equations,

$$
\varepsilon^{-1}=\frac{\left(2 \beta_{\mathrm{HHI}^{2}}-\beta_{\mathrm{HHI}}\right)^{2}}{4 \beta_{\mathrm{HHI}^{2}}-\beta_{\mathrm{HHI}}} .
$$

Using the estimates from Table 3 and Equation 14 delivers values for the implied inverse labor market elasticity, $\varepsilon^{-1}$. The coefficients in specification (1) and (3) imply $\varepsilon^{-1}=.4$ and $\varepsilon^{-1}=.23$, respectively. These correspond to an elasticity of labor between 2.5 and 4 . There are two different but observationally equivalent interpretations of this elasticity. First, it can be interpreted as the average elasticity of the labor supply faced by firms. Second, it can be interpreted as the labor supply elasticity of employees making a non-dynamic labor supply decision. Further complicating the interpretation of the implied labor supply elasticity is that the unit of observation in this data set is jobs as opposed to hours. In any case, however, these estimates should not be interpreted as estimates of the Frisch elasticity of labor supply. Finally, Specifications (2) and (4) include controls for the total size of the labor market. The labor supply elasticities implied by these specifications are negative because labor supply is not allowed to adjust normally.

\subsection{The Relationship between the Labor Share and Concentration}

While the preceding section connected labor market concentration to wages, I have yet to say anything about the labor share. This section makes the connection between labor market concentration 
and the labor share and shows the labor market concentration is not driving the falling labor share.

The labor share is the proportion of output that goes to compensating labor

$$
\alpha=\frac{w L}{P Y}=\frac{w}{P}\left(\frac{Y}{L}\right)^{-1}
$$

where $w$ is average compensation, $L$ is total employment, $P$ is the price level and $Y$ is total output, $w L$ is the total compensation paid to labor while $P Y$ is the total value of output. The third expression in Equation 15 shows that the labor share is the ratio of real wages, $\frac{w}{P}$ to real labor productivity, $\left(\frac{Y}{L}\right)^{-1}$.

The aggregate real compensation in Equation 15 is the employment-weighted average of the real compensation in all of the labor markets in the U.S. That is, for $M$ labor markets in the U.S. indexed by $m$,

$$
\frac{w}{P}=\frac{\sum_{m=1}^{M} \omega_{m}}{P L}=\sum_{m=1}^{M} \frac{P_{m} L_{m}}{P L} \frac{\omega_{m}}{P_{m} L_{m}}
$$

where $\omega_{m}$ is the total compensation in labor market $m$, and $L_{m}$ is the employment in labor market $m$. Here, $\frac{\omega_{m}}{L_{m}}$ is the same as the wage calculated in Equation 6 because the model does not distinguish between wages and compensation. Inserting the relationship between concentration and labor market wages as $f(h)$ from 6 and adding time subscripts yields

$$
\omega_{t}=\sum_{m=1}^{M} \frac{L_{m t}}{L_{t}} \exp \left(f\left(h_{m, t}, \Gamma_{m, t}\right)\right)
$$

where $f(\cdot)$ is a nonlinear function, $\Gamma_{m, t}$ is a vector of variables other than the labor market concentration that determine wages in market $m$ at time $t$ and $h_{t}$ is the labor market concentration in market $m$ at time $t$. Because of the non-linearity of the $\exp ()$, there is not a simple decomposition for changes in $\omega$. However, taking the first order approximation of the expression around the points 
$\bar{h}$ and $\bar{\Gamma}$, and rearranging the expression yields

$$
\begin{aligned}
\omega_{t} \approx & \exp (f(\bar{h}, \bar{\Gamma}))\left(1-f_{h}(\bar{h}, \bar{\Gamma}) \bar{h}-f_{\Gamma}(\bar{h}, \bar{\Gamma}) \bar{\Gamma}\right)+f_{h}(\bar{h}, \bar{\Gamma}) \exp (f(\bar{h}, \bar{\Gamma})) \sum_{m=1}^{M} \frac{L_{m t}}{L_{t}} h_{m, t} \\
& +f_{\Gamma}(\bar{h}, \bar{\Gamma}) \exp (f(\bar{h}, \bar{\Gamma})) \sum_{m=1}^{M} \frac{L_{m t}}{L_{t}} \Gamma_{m, t}
\end{aligned}
$$

Substitute $\zeta(\bar{h}, \bar{\Gamma}) \equiv \exp (f(\bar{h}, \bar{\Gamma}))\left(1-f_{h}(\bar{h}, \bar{\Gamma}) \bar{h}-f_{\Gamma}(\bar{h}, \bar{\Gamma}) \bar{\Gamma}\right), \delta(\bar{h}, \bar{\Gamma}) \equiv f_{h}(\bar{h}, \bar{\Gamma}) \exp (f(\bar{h}, \bar{\Gamma}))$ and $\psi(\bar{h}, \bar{\Gamma}) \equiv f_{\Gamma}(\bar{h}, \bar{\Gamma}) \exp (f(\bar{h}, \bar{\Gamma}))$ to get

$$
\approx \zeta(\bar{h}, \bar{\Gamma})+\delta(\bar{h}, \bar{\Gamma}) \sum_{m=1}^{M} \frac{L_{m t}}{L_{t}} h_{t}+\psi(\bar{h}, \bar{\Gamma}) \sum_{m=1}^{M} \frac{L_{m t}}{L_{t}} \Gamma_{m, t}
$$

Note that $\zeta(\bar{h}, \bar{\Gamma}), \psi(\bar{h}, \bar{\Gamma})$, and $\delta(\bar{h}, \bar{\Gamma})$ are time invariant functions of $\bar{h}$ and $\bar{\Gamma}$. Equation 19 demonstrates that, to a first approximation, the aggregate compensation depends on the employmentweighted average concentration of the labor markets and the employment-weighted average of $\Gamma$, the other variables that determine wages within the labor market. Using this approximation, the change in aggregate wages due to changing labor market concentration is

$$
\Delta \omega=\omega_{2}-\omega_{1} \approx \delta(\bar{h}, \bar{\Gamma})\left[\sum_{m=1}^{M_{2}} \frac{L_{m 2}}{L_{2}} h_{2}-\sum_{m=1}^{M_{1}} \frac{L_{m 1}}{L_{1}} h_{1}\right] .
$$

Because $\psi((\bar{h}, \bar{\Gamma}))$ does not depend on $h_{m, t}$, it is invariant to changes in the labor market concentration. It therefore does not factor into changes in the labor share due to change in labor market concentration.

Figure 2 shows the time series of the employment-weighted average labor market concentration from 1980 to 2012. The employment-weighted average labor market concentration has decreased since 1980. Because $f_{h}(h, \Gamma)<0, \delta(\bar{h}, \bar{\Gamma})<0$. Therefore, this time series trend is the opposite of what is needed to explain the declining labor share. Of possible concern, however, is that this decline in the employment-weighted average labor market concentration is caused by the changing geographic definitions. To examine this possibility, I have calculated the time series of the employment-weighted average labor market concentration using fixed city definitions. Because 
these results have not yet been disclosed by the Census Bureau, they cannot be discussed in detail here, but Rinz (2018) contemporaneously finds similar local dynamics using both the Commuting Zone and the County definitions of labor markets. These similar findings show that the direction of the changes in the employment-weighted average labor market concentration is not driven by changing geographical definitions.

Figure 3 shows the component of the labor share driven only by changes in the employmentweighted average labor market concentration. I calculate $\delta(\bar{h}, \bar{\Gamma})$ using the estimates of Equation 10 in Column (2) of Table 3 for the coefficients on Hस̈I, the mean of the labor market concentration for $\bar{h}$, and have set $\bar{\Gamma}=0$ so that individual time and market components do not affect the aggregate trend. These choices lead to

$$
\delta(\bar{h}, \bar{\Gamma})=(-.0875-2 \cdot .0411 \cdot .55) \exp \left(-.0875 \cdot .55-.0411 \cdot .55^{2}\right)=-.173
$$

The regression analysis of Section 5.1 links the labor market concentration with wages instead of total compensation. According to the BLS's Employment Costs for Employee Compensation (ECEC) survey, ${ }^{4}$ however, wages made up $73 \%$ of total compensation in 1986 (the first year of data) and $69.3 \%$ of total compensation in 2012. While wages' share of compensation has declined slightly, as long as both wages and other benefits respond to labor market concentration in the same way, this calculation makes sense. The calculation starts .63 based on the labor share in 1980 in the Penn World Table. ${ }^{5}$ This graph makes it clear that the employment-weighted labor market concentration is moving in the wrong direction to cause the falling labor share.

The aggregate trend in employment-weighted average labor market concentration, however, masks qualitative differences in industry trends. Figure 4 shows the employment-weighted average labor market concentration by industry. It shows that the employment-weighted average labor market concentration has increased in retail trade, manufacturing, wholesale trade, and finance, insurance and real estate (FIRE). The employment-weighted average labor market concentration, however, has fallen in services and transport, warehousing and utilities. Because services has become a much more bigger employer within the U.S. economy, its decreasing employment-weighted average

\footnotetext{
${ }^{4}$ Available from the BLS https://www.bls.gov/ncs/ect/\#tables

${ }^{5}$ Available from the St. Louis Fed: https://fred.stlouisfed.org/series/LABSHPUSA156NRUG
} 
labor market concentration helps drive the aggregate trend. Examining the employment-weighted average labor market concentration is tantamount to examining the labor market concentration faced by the average U.S. worker. The implication of Figure 2 is that the average U.S. worker is facing a lower labor market concentration today than he did 30 years ago. Additionally, the trend in manufacturing is especially interesting because it is the trend identified and explored in Benmelech et al. (2018). However, because they focus on manufacturing and ignore the employment weighting needed to examine the aggregate, their conclusions are incorrect.

The time series dynamics of the employment-weighted average labor market concentration is not only driven by the shifting work force. Figure 5 shows that the equal-weighted average labor market concentration has also decreased from 1980 to 2012. This aggregate trend also covers qualitative differences among industries. Figure 6 shows the equal-weighted average labor market concentration by industry.

The preceding discussion focused entirely on the relationship between aggregate real compensation, $\frac{w}{P}$, and local labor market concentration without discussing the other piece of total

compensation $\left(\frac{Y}{L}\right)^{-1}$, labor productivity. If local labor market concentration is a measure of monopsony power, and monopsony in labor markets increases labor productivity, then the employmentweighted average labor market concentration would have to increase in order to reduce the labor share. However, both the employment-weighted average and equal-weighted average labor market concentrations decrease over the time period.

\section{Extensions}

This section provides extensions to the main analysis of the paper. First, I examine the relationship between labor market concentration and wages through time and find that has weakened (become less negative). Second, I extend the model presented in Section 3 to incorporate product market power as well as labor market concentration. When product market power is included, the relationship between wages and labor market concentration is accentuated. The results of this extension are consistent with the literature on increasing product market concentration as a measure of product market power driving the falling labor share. 


\subsection{Labor Market Concentration and Wages Through Time}

While Section 5.2 shows that the time series of labor market concentration moves in the opposite direction necessary to explain the falling labor share, this analysis was based on a static relationship between wages and labor market concentration. If, however, the relationship between labor market concentration and wages has been strengthening, that is, getting bigger in absolute value terms, then labor market concentration could still be driving the falling labor share. This change is tantamount to $\delta(\bar{h}, \bar{\Gamma})$ in Section 5.2 becoming more negative. To examine this possibility, I divide my sample into sub-periods and regress wages on concentration. I find that the relationship between labor market concentration and wages has also weakened over the period of study.

Table 2 shows the summary statistics for each sub-period: the number of observations, the average HHI and the employment-weighted average HHI. The number of observations goes up monotonically, but the average HHI and employment-weighted average HHI are remarkably stable. As before, the standard deviations are in parentheses underneath the mean.

The specification I use for this analysis is

$$
\log \left(w_{m t}\right)=\alpha_{i t}+\alpha_{c t}+\alpha_{m}+\beta_{1} \mathrm{HHI}_{m t}+\beta_{2} \mathrm{HHI}_{m t}^{2}+\varepsilon_{m t}
$$

I have dropped the additional labor market controls because they do not change the estimates much but have included the city-by-time and the industry-by-time fixed effects. The results of the regression are presented in Table 5. Most importantly, the marginal effect at the mean has been decreasing since the earliest sub-periods. Figure 7 emphasizes this result. It shows the time series of the marginal effect at the mean of HHI on wages. The effect at the mean is getting closer to 0 . These results allay any fears that changes in the relationship between labor market concentration and wages could be driving the declining labor share.

\subsection{Adding Product Market Power}

Another possible concern with regressing wages on labor market concentration is that product market power could contaminate the estimated relationship. In this final extension of the analysis, 
I control for product market power by dividing firms into local and tradable industries. Implicitly this assumes that product market power is uncorrelated with local labor market concentration for firms operating in tradable goods. I allow the output good to have a price $P(q)$ that depends on the quantity produced and $q=\sum_{i=1}^{N} q_{i}$. Because $P(q)$ is the inverse demand curve, $P^{\prime}(q)<0$. Firms have the same production technology and information as described in Section 3. Additionally, firms know how their production will affect the price of their output good. The firm's first order condition is then

$$
P^{\prime}(q) A_{i}^{2} l_{i}+P(q) A_{i}-w^{\prime}(L) l_{i}-w(L)=0
$$

which leads to

$$
\log (w)=\log (\bar{A})+\log \left(\frac{P(q) \bar{A} L+P(q) \sum_{i=1}^{N} a_{i} l_{i}}{\bar{A} L}\right)-\log \left(1+\left(\varepsilon^{-1}-\frac{P^{\prime}(q) A_{i}^{2} L}{w}\right) \mathrm{HHI}\right) .
$$

Because of the additional marginal revenue term, the relationship between the concentration, HHI, and the wage is now more negative. Intuitively, in these markets, firms have incentives to restrict their hiring because of the profits they will earn in both the product market and the labor market.

The definitions for tradable versus local goods come from Delgado et al. (2015). Their methodology classifies each 6-digit NAICS classification as either tradable or local. Local industries are those whose employment is more evenly distributed throughout the country because the goods and services are location-based like food service and retail. Tradable industries, on the other hand, are more geographically concentrated. Because these industries can ship their goods, they are able to cluster more readily and benefit from agglomeration externalities. The analysis in this paper uses 5-digit NAICS and the Delgado et al. (2015) classifications are at the 6-digit NAICS level. This mismatch creates an additional category in this analysis: "Both." There are potentially 10 6-digit NAICS categories in each 5-digit NAICS category. If all of the 6-digit NAICS codes within a 5-digit code belong to the same classification, then the 5-digit code gets that classification. If, on the other, there are conflicting 6-digit classifications, then the 5-digit NAICS code is designated "Both."

In the regression specification, I allow all variables to vary by tradable, local, or both. The 
exact specification I use is

$$
\begin{aligned}
w_{m t}=\alpha & +\beta_{1} \mathrm{HHI}_{m t}+\beta_{2} \mathbb{1}[\text { Local }] * \mathrm{HHI}_{m t}+\beta_{3} \mathbb{1}[\text { Both }] * \mathrm{HHI}_{m t}+\beta_{4} \mathrm{HHI}_{m t}^{2}+ \\
& \beta_{5} \mathbb{1}[\text { Local }] * \mathrm{HHI}_{m t}^{2}+\beta_{6} \mathbb{1}[\text { Both }] * \mathrm{HHI}_{m t}^{2}+\beta_{7} \Psi_{m t}+\beta_{8} \mathbb{1}[\text { Local }] * \Psi_{m t}+ \\
& \beta_{9} \mathbb{1}[\text { Both }] * \Psi_{m t}+\varepsilon_{m t}
\end{aligned}
$$

where $\alpha$ is various fixed effects, $\mathbb{1}[\cdot]$ is an indicator function, and $\Psi_{m t}$ is the set of market-level controls for total employment and the number of firms in the market. The fixed effects structures mirror those in Section 5.1.2.

Table 4 presents the results from this regression. In all the specifications, the estimated coefficient $\hat{\beta}_{\mathbb{1}[\text { Local }] * \text { HHI }}$ is negative and significant at the $1 \%$ level indicating that, in line with the theory, wages in industries that produce local goods have a stronger relationship with the labor market concentration than wages in industries that produce tradable goods or industries that produce both. Additionally, the estimated coefficient $\hat{\beta}_{\mathbb{1}[\text { Local }] * \mathrm{HHI}^{2}}$ is positive and significant at the $1 \%$ level in all specifications indicating that while local goods producers have a stronger first order effects of concentration on wages, these effects are less non-linear than in tradable goods. Column (2) shows the results of the specification without additional controls but with city-bytime and industry-by-time fixed effects. In this estimate, tradable goods' relationship between wages and labor market concentration has a small, but not statistically significant, main effect of the relationship between their wages and the labor market concentration (-.0227) but a large nonlinear effect (-.1479). Local goods, however, have the opposite relationship. The main effect of concentration on wages for local goods producing industries is large $(-.1434=-.0227+-.1207)$ and the nonlinear effect is much smaller $(-.0394=-.1479+.1085)$. The results in specifications $(3)$ and (4) follow the same pattern-local goods have stronger relationship between wages and concentration than tradable goods do.

These findings are in line with the current literature on product market concentration. Product market concentration has been increasing, and if this increase in concentration is accompanied by an increase in product market power, it would decrease the labor share as in this model extension. This line of reasoning matches that in Barkai (2016) and in De Loecker and Eeckhout (2017). 
Additionally, the negative relationship between labor market concentration and wages is robust to controlling for product market power, even if it contaminates the initial point estimates.

\section{Conclusion}

This paper shows that labor market concentration is an implausible driver of the falling labor share. The time series trend in employment-weighted average labor market concentration moves opposite to what is needed to explain the falling labor share, and the relationship between wages and labor market concentration has not strengthed. Additionally, product market concentration is a plausible driver of the falling labor share as its time series trend moves in the right direction and product market power intensifies the relationship between wages and labor market concentration.

Taken together, these results suggest labor market concentration is a diminishing, not an increasing, problem for U.S. workers. Recent calls to update regulatory regimes to incorporate or prioritize labor market concentration in order to respond to the falling labor share and stagnating wages are, therefore, premature and unsupported by the evidence. 


\section{References}

David Autor, David Dorn, Lawrence F Katz, Christina Patterson, John Van Reenen, et al. The fall of the labor share and the rise of superstar firms. National Bureau of Economic Research, 2017.

José Azar, Ioana Marinescu, and Marshall I Steinbaum. Labor market concentration. Technical report, National Bureau of Economic Research, 2017.

José A Azar, Ioana Marinescu, Marshall I Steinbaum, and Bledi Taska. Concentration in us labor markets: Evidence from online vacancy data. Technical report, National Bureau of Economic Research, 2018.

Simcha Barkai. Declining labor and capital shares. University of Chicago, November, 2016.

Keith Barnatchez, Leland Crane, and Ryan Decker. An assessment of the national establishment time series (nets) database. 2017.

Alexander W Bartik. Worker adjustment to changes in labor demand: Evidence from longitudinal census data. Technical report, Working paper, 2017.

Efraim Benmelech, Nittai Bergman, and Hyunseob Kim. Strong employers and weak employees: How does employer concentration affect wages? Technical report, National Bureau of Economic Research, 2018.

Nick Bloom, Fatih Guvenen, David J Price, Jae Song, et al. Firming up inequality. Technical report, Centre for Economic Performance, LSE, 2015.

William M Boal and Michael R Ransom. Monopsony in the labor market. Journal of economic literature, 35(1):86-112, 1997.

Jan De Loecker and Jan Eeckhout. The rise of market power. 2017.

Mercedes Delgado, Michael E Porter, and Scott Stern. Defining clusters of related industries. Journal of Economic Geography, 16(1):1-38, 2015.

Andrew Foote, Mark J Kutzbach, and Lars Vilhuber. Recalculating-how uncertainty in local labor market definitions affects empirical findings. 2017. 
Teresa C Fort and Shawn D Klimek. The effect of industry classification changes on us employment composition. Tuck School at Dartmouth, 2016.

Cecile Gaubert. Firm sorting and agglomeration. Technical report, National Bureau of Economic Research, 2018.

John Haltiwanger, Ron S Jarmin, and Javier Miranda. Who creates jobs? small versus large versus young. Review of Economics and Statistics, 95(2):347-361, 2013.

Ron S Jarmin and Javier Miranda. The longitudinal business database. 2002.

Matthias Kehrig and Nicolas Vincent. Growing productivity without growing wages: The microlevel anatomy of the aggregate labor share decline. 2017.

Alan B. Krueger. Reflections on dwindling worker bargaining power and monetary policy, August 2018. URL https://www.kansascityfed.org/ /media/files/publicat/sympos/2018/ kcfedlunchremarks-aspreparedfordeliveryv2.pdf?la=en. Luncheon Address at the Jackson Hole Economic Symposium.

Alan Manning and Barbara Petrongolo. How local are labor markets? evidence from a spatial job search model. American Economic Review, 107(10):2877-2907, 2017.

Ioana Marinescu and Roland Rathelot. Mismatch unemployment and the geography of job search. Technical report, National Bureau of Economic Research, 2016.

Ioana Elena Marinescu and Herbert Hovenkamp. Anticompetitive mergers in labor markets. 2018.

Raven Molloy, Christopher L Smith, and Abigail K Wozniak. Declining migration within the us: the role of the labor market. Technical report, National Bureau of Economic Research, 2014.

Dale T Mortensen. Wage dispersion: why are similar workers paid differently? MIT press, 2005.

Suresh Naidu, Eric A Posner, and E Glen Weyl. Antitrust remedies for labor market power. 2018.

Walter Y Oi and Todd L Idson. Firm size and wages. Handbook of labor economics, 3:2165-2214, 1999.

Mark D Partridge, Dan S Rickman, M Rose Olfert, and Kamar Ali. Dwindling us internal migration: 
Evidence of spatial equilibrium or structural shifts in local labor markets? Regional Science and Urban Economics, 42(1-2):375-388, 2012.

Kevin Rinz. Labor market concentration, earnings inequality, and earnings mobility. Technical report, U.S. Census Bureau CARRA Working Paper Series, 2018.

Esteban Rossi-Hansberg, Pierre-Daniel Sarte, and Nicholas Trachter. Diverging trends in national and local concentration. 2018. 
Table 1: Summary stats for the full sample, 1980-2012

\begin{tabular}{lc}
\hline & Full Sample \\
\cline { 2 - 2 } Observations & $6,940,000$ \\
HHI & 0.5499 \\
& $(0.3517)$ \\
$\ln \left(\right.$ Aggregate Wage $\left._{m t}\right)$ & 9.833 \\
& $(0.9535)$ \\
$\ln \left(\right.$ emp $\left._{m}\right)$ & 3.652 \\
& $(2.038)$ \\
$n_{m t}$ & 19 \\
& $(137.7)$ \\
Annual Markets & 210,300 \\
& $(15,840)$ \\
Employment-weighted HHI & 0.189 \\
& 0.25 \\
\hline
\end{tabular}


Table 2: Observation counts, Average HHI, and Employment-weighted Average HHI for each sub-sample

\begin{tabular}{|c|c|c|c|c|c|c|c|c|}
\hline Period & $1980-1983$ & $1984-1988$ & 1989-1992 & 1993-1996 & $1997-2000$ & $2001-2004$ & $2005-2008$ & 2009-2012 \\
\hline Observations & 740,000 & 770,000 & 800,000 & 830,000 & 860,000 & 890,000 & 930,000 & $1,130,000$ \\
\hline HHI & $\begin{array}{c}0.554 \\
(0.354)\end{array}$ & $\begin{array}{c}0.557 \\
(0.354)\end{array}$ & $\begin{array}{c}0.554 \\
(0.354)\end{array}$ & $\begin{array}{c}0.547 \\
(0.353)\end{array}$ & $\begin{array}{c}0.547 \\
(0.352)\end{array}$ & $\begin{array}{l}0.547 \\
(0.35)\end{array}$ & $\begin{array}{c}0.545 \\
(0.349)\end{array}$ & $\begin{array}{c}0.545 \\
(0.349)\end{array}$ \\
\hline Employment weighted HHI & $\begin{array}{l}0.203 \\
(0.27)\end{array}$ & $\begin{array}{c}0.196 \\
(0.267)\end{array}$ & $\begin{array}{c}0.189 \\
(0.259)\end{array}$ & $\begin{array}{c}0.188 \\
(0.257)\end{array}$ & $\begin{array}{c}0.187 \\
(0.252)\end{array}$ & $\begin{array}{c}0.188 \\
(0.249)\end{array}$ & $\begin{array}{c}0.185 \\
(0.246)\end{array}$ & $\begin{array}{c}0.184 \\
(0.245)\end{array}$ \\
\hline
\end{tabular}


Table 3: The relationship between HHI and aggregate wages with controls

\begin{tabular}{|c|c|c|c|c|}
\hline & \multicolumn{4}{|c|}{ Dependent Variable $\ln ($ Aggregate Wage $)$} \\
\hline & $(1)$ & $(2)$ & $(3)$ & $(4)$ \\
\hline$\hat{\beta}_{\mathrm{HHI}}$ & $\begin{array}{c}-0.1982^{* * *} \\
{[0.0116]}\end{array}$ & $\begin{array}{c}-0.0875^{* * *} \\
{[0.0105]}\end{array}$ & $\begin{array}{c}-0.2257^{* * *} \\
{[0.0119]}\end{array}$ & $\begin{array}{c}-0.1170 * * * \\
{[0.0105]}\end{array}$ \\
\hline$\hat{\beta}_{\mathrm{HHI}^{2}}$ & $\begin{array}{c}-0.0411^{* * *} \\
{[0.0087]}\end{array}$ & $\begin{array}{c}-0.0902^{* * *} \\
{[0.0078]}\end{array}$ & $\begin{array}{l}-0.0007 \\
{[0.0089]}\end{array}$ & $\begin{array}{c}-0.0456^{* * *} \\
{[0.0078]}\end{array}$ \\
\hline$\hat{\beta}_{\ln (\mathrm{emp})}$ & & & $\begin{array}{c}0.0176^{* * *} \\
{[0.0008]}\end{array}$ & $\begin{array}{c}0.0226^{* * *} \\
{[0.0008]}\end{array}$ \\
\hline$\hat{\beta}_{n}$ & & & $\begin{array}{c}-0.0006^{* * *} \\
{[0.0001]}\end{array}$ & $\begin{array}{c}-0.0003^{* * *} \\
{[0.0000]}\end{array}$ \\
\hline $\begin{array}{l}\text { Obs } \\
R^{2}\end{array}$ & $\begin{array}{c}6940000 \\
0.4432\end{array}$ & $\begin{array}{c}6940000 \\
0.5759\end{array}$ & $\begin{array}{c}6940000 \\
0.4437\end{array}$ & $\begin{array}{c}6940000 \\
0.5762\end{array}$ \\
\hline $\begin{array}{l}\text { Marginal Effect at the Mean } \\
\text { Effect of } 1 \text { SD Increase from Mean }\end{array}$ & $\begin{array}{l}-0.2434 \\
-0.0907\end{array}$ & $\begin{array}{l}-0.1867 \\
-0.0768\end{array}$ & $\begin{array}{l}-0.2265 \\
-0.0797\end{array}$ & $\begin{array}{l}-0.1672 \\
-0.0644\end{array}$ \\
\hline $\begin{array}{l}\text { Time FE } \\
\text { Industry } \times \text { City FE } \\
\text { Time } \times \text { City FE } \\
\text { Time } \times \text { Industry FE }\end{array}$ & $\begin{array}{l}\mathrm{X} \\
\mathrm{X}\end{array}$ & $\begin{array}{l}X \\
X \\
X\end{array}$ & $\begin{array}{l}\mathrm{X} \\
\mathrm{X}\end{array}$ & $\begin{array}{l}X \\
X \\
X\end{array}$ \\
\hline
\end{tabular}


Table 4: The relationship between HHI and aggregate wages with controls, tradable vs local

\begin{tabular}{|c|c|c|c|c|}
\hline & \multicolumn{4}{|c|}{ Dependent Variable $\ln$ (Aggregate Wage) } \\
\hline & $(1)$ & $(2)$ & $(3)$ & $(4)$ \\
\hline$\hat{\beta}_{\mathrm{HHI}}$ & $\begin{array}{c}-0.1154^{* * *} \\
{[0.0170]}\end{array}$ & $\begin{array}{l}-0.0227 \\
{[0.0159]}\end{array}$ & $\begin{array}{c}-0.1619^{* * *} \\
{[0.0171]}\end{array}$ & $\begin{array}{c}-0.0875 * * * \\
{[0.0159]}\end{array}$ \\
\hline$\hat{\beta}_{\mathbb{I}[\text { Local }] * \mathrm{HHI}}$ & $\begin{array}{c}-0.1665^{* * *} \\
{[0.0236]}\end{array}$ & $\begin{array}{c}-0.1207^{* * *} \\
{[0.0215]}\end{array}$ & $\begin{array}{c}-0.1658^{* * *} \\
{[0.0240]}\end{array}$ & $\begin{array}{c}-0.0638^{* * *} * \\
{[0.0215]}\end{array}$ \\
\hline$\hat{\beta}_{\mathbb{1}[\text { Both }] * \mathrm{HHI}}$ & $\begin{array}{c}0.1397^{* * * *} \\
{[0.0512]}\end{array}$ & $\begin{array}{l}-0.0308 \\
{[0.0468]}\end{array}$ & $\begin{array}{c}0.1155^{* *} \\
{[0.0523]}\end{array}$ & $\begin{array}{l}-0.0762 \\
{[0.0466]}\end{array}$ \\
\hline$\hat{\beta}_{\mathrm{HHI}^{2}}$ & $\begin{array}{c}-0.1119^{* * *} \\
{[0.0125]}\end{array}$ & $\begin{array}{c}-0.1479^{* * *} \\
{[0.0117]}\end{array}$ & $\begin{array}{c}-0.0362^{* * *} \\
{[0.0126]}\end{array}$ & $\begin{array}{c}-0.0686^{* * *} \\
{[0.0117]}\end{array}$ \\
\hline$\hat{\beta}_{\mathbb{1}[\text { Local }] * \mathrm{HHI}^{2}}$ & $\begin{array}{c}0.1438^{* * * *} \\
{[0.0177]}\end{array}$ & $\begin{array}{c}0.1085^{* * *} \\
{[0.0161]}\end{array}$ & $\begin{array}{c}0.0842^{* * * *} \\
{[0.0179]}\end{array}$ & $\begin{array}{c}0.0379 * * \\
{[0.0161]}\end{array}$ \\
\hline$\hat{\beta}_{\mathbb{1}[\text { Both }] * \mathrm{HHI}^{2}}$ & $\begin{array}{c}-0.0895^{* *} \\
{[0.0383]}\end{array}$ & $\begin{array}{c}0.0496 \\
{[0.0351]}\end{array}$ & $\begin{array}{l}-0.0586 \\
{[0.0393]}\end{array}$ & $\begin{array}{c}0.1001^{* * *} \\
{[0.0352]}\end{array}$ \\
\hline$\hat{\beta}_{\ln (\mathrm{emp})}$ & & & $\begin{array}{c}0.0349 * * * \\
{[0.0010]}\end{array}$ & $\begin{array}{c}0.0320^{* * *} \\
{[0.0010]}\end{array}$ \\
\hline$\hat{\beta}_{\mathbb{I}[\text { Local }] * \ln (\mathrm{emp})}$ & & & $\begin{array}{c}-0.0465^{* * *} \\
{[0.0017]}\end{array}$ & $\begin{array}{c}-0.0291^{* * *} \\
{[0.0017]}\end{array}$ \\
\hline$\hat{\beta}_{\mathbb{1}[\text { Both }] * \ln (\mathrm{emp})}$ & & & $\begin{array}{c}0.0150^{* * *} \\
{[0.0036]}\end{array}$ & $\begin{array}{c}0.0244^{* * *} \\
{[0.0035]}\end{array}$ \\
\hline$\hat{\beta}_{n}$ & & & $\begin{array}{c}-0.0004^{* * *} \\
{[0.0001]}\end{array}$ & $\begin{array}{c}-0.0003^{* * *} * \\
{[0.0000]}\end{array}$ \\
\hline$\hat{\beta}_{\mathbb{1}[\text { Local }] * n}$ & & & $\begin{array}{c}-0.0002^{* *} \\
{[0.0001]}\end{array}$ & $\begin{array}{c}0.0001 \\
{[0.0001]}\end{array}$ \\
\hline$\hat{\beta}_{\mathbb{1}[\text { Both }] * n}$ & & & $\begin{array}{c}-0.0008^{* * *} \\
{[0.0003]}\end{array}$ & $\begin{array}{c}0.0001 \\
{[0.0001]}\end{array}$ \\
\hline $\begin{array}{l}\text { Obs } \\
R^{2}\end{array}$ & $\begin{array}{c}6940000 \\
0.4432\end{array}$ & $\begin{array}{c}6940000 \\
0.5759\end{array}$ & $\begin{array}{c}6940000 \\
0.4441\end{array}$ & $\begin{array}{c}6940000 \\
0.5763\end{array}$ \\
\hline $\begin{array}{l}\text { Marginal Effect At .55, Tradable } \\
\text { Marginal Effect At .55, Local }\end{array}$ & $\begin{array}{l}-0.238 \\
-0.247\end{array}$ & $\begin{array}{l}-0.202 \\
-0.275\end{array}$ & $\begin{array}{l}-0.185 \\
-0.187\end{array}$ & $\begin{array}{l}-0.163 \\
-0.185\end{array}$ \\
\hline $\begin{array}{l}\text { Time FE } \\
\text { Industry } \times \text { City FE } \\
\text { Time } \times \text { City FE } \\
\text { Time } \times \text { Industry FE }\end{array}$ & $\begin{array}{l}X \\
X\end{array}$ & $\begin{array}{l}X \\
X \\
X\end{array}$ & $\begin{array}{l}X \\
X\end{array}$ & $\begin{array}{l}X \\
X \\
X\end{array}$ \\
\hline
\end{tabular}


Table 5: The relationship between HHI and aggregate wages with controls, through time

\begin{tabular}{|c|c|c|c|c|c|c|c|c|}
\hline \multirow[b]{2}{*}{ Period } & \multicolumn{8}{|c|}{ Dependent Variable $\ln ($ Aggregate Wage $)$} \\
\hline & $1980-1983$ & 1984-1988 & 1989-1992 & 1993-1996 & $1997-2000$ & 2001-2004 & $2005-2008$ & 2009-2012 \\
\hline$\hat{\beta}_{\mathrm{HHI}}$ & $\begin{array}{c}-0.5128^{* * *} \\
{[0.0561]}\end{array}$ & $\begin{array}{c}-0.6923^{* * *} \\
{[0.0592]}\end{array}$ & $\begin{array}{c}-0.5848^{* * *} \\
{[0.0356]}\end{array}$ & $\begin{array}{c}-0.4027^{* * *} \\
{[0.0206]}\end{array}$ & $\begin{array}{c}-0.0402^{* *} \\
{[0.0176]}\end{array}$ & $\begin{array}{c}-0.1181^{* * *} \\
{[0.0179]}\end{array}$ & $\begin{array}{c}-0.2960^{* * *} \\
{[0.0191]}\end{array}$ & $\begin{array}{c}-0.1915^{* * *} \\
{[0.0179]}\end{array}$ \\
\hline$\hat{\beta}_{\mathrm{HHI}^{2}}$ & $\begin{array}{c}0.1684^{* * *} \\
{[0.0405]}\end{array}$ & $\begin{array}{c}0.2836^{* * *} \\
{[0.0424]}\end{array}$ & $\begin{array}{c}0.3198^{* * *} \\
{[0.0259]}\end{array}$ & $\begin{array}{c}0.2550^{* * *} \\
{[0.0160]}\end{array}$ & $\begin{array}{c}-0.0552^{* * *} \\
{[0.0140]}\end{array}$ & $\begin{array}{c}0.0047 \\
{[0.0142]}\end{array}$ & $\begin{array}{c}0.1369^{* * *} \\
{[0.0150]}\end{array}$ & $\begin{array}{c}0.0827^{* * *} \\
{[0.0139]}\end{array}$ \\
\hline $\begin{array}{l}\text { Obs } \\
R^{2}\end{array}$ & $\begin{array}{c}740000 \\
0.7098\end{array}$ & $\begin{array}{l}770000 \\
0.7001\end{array}$ & $\begin{array}{c}800000 \\
0.6694\end{array}$ & $\begin{array}{c}830000 \\
0.87\end{array}$ & $\begin{array}{c}860000 \\
0.8523\end{array}$ & $\begin{array}{c}890000 \\
0.848\end{array}$ & $\begin{array}{c}930000 \\
0.8772\end{array}$ & $\begin{array}{c}1130000 \\
0.8688\end{array}$ \\
\hline $\begin{array}{l}\text { Mean HHI Within Sample } \\
\text { Standard Deviation HHI Within Sample }\end{array}$ & $\begin{array}{l}0.554 \\
0.354\end{array}$ & $\begin{array}{l}0.557 \\
0.354\end{array}$ & $\begin{array}{l}0.554 \\
0.354\end{array}$ & $\begin{array}{l}0.547 \\
0.353\end{array}$ & $\begin{array}{l}0.547 \\
0.352\end{array}$ & $\begin{array}{c}0.547 \\
0.35\end{array}$ & $\begin{array}{l}0.545 \\
0.349\end{array}$ & $\begin{array}{l}0.545 \\
0.349\end{array}$ \\
\hline Marginal Effect at the Mean & -0.326 & -0.376 & -0.23 & -0.124 & -0.101 & -0.113 & -0.147 & -0.101 \\
\hline Industry $\times$ City FE & $\mathrm{X}$ & $\mathrm{X}$ & $\mathrm{X}$ & $\mathrm{X}$ & $\mathrm{X}$ & $\mathrm{X}$ & $\mathrm{X}$ & $\mathrm{X}$ \\
\hline Time $\times$ City FE & $\mathrm{X}$ & $\mathrm{X}$ & $\mathrm{X}$ & $\mathrm{X}$ & $\mathrm{X}$ & $\mathrm{X}$ & $\mathrm{X}$ & $\mathrm{X}$ \\
\hline Time $\times$ Industry FE & $\mathrm{X}$ & $\mathrm{X}$ & $\mathrm{X}$ & $\mathrm{X}$ & $\mathrm{X}$ & $\mathrm{X}$ & $\mathrm{X}$ & $\mathrm{X}$ \\
\hline
\end{tabular}


Figure 1: Total employment covered by sample, 1980-2012, in millions

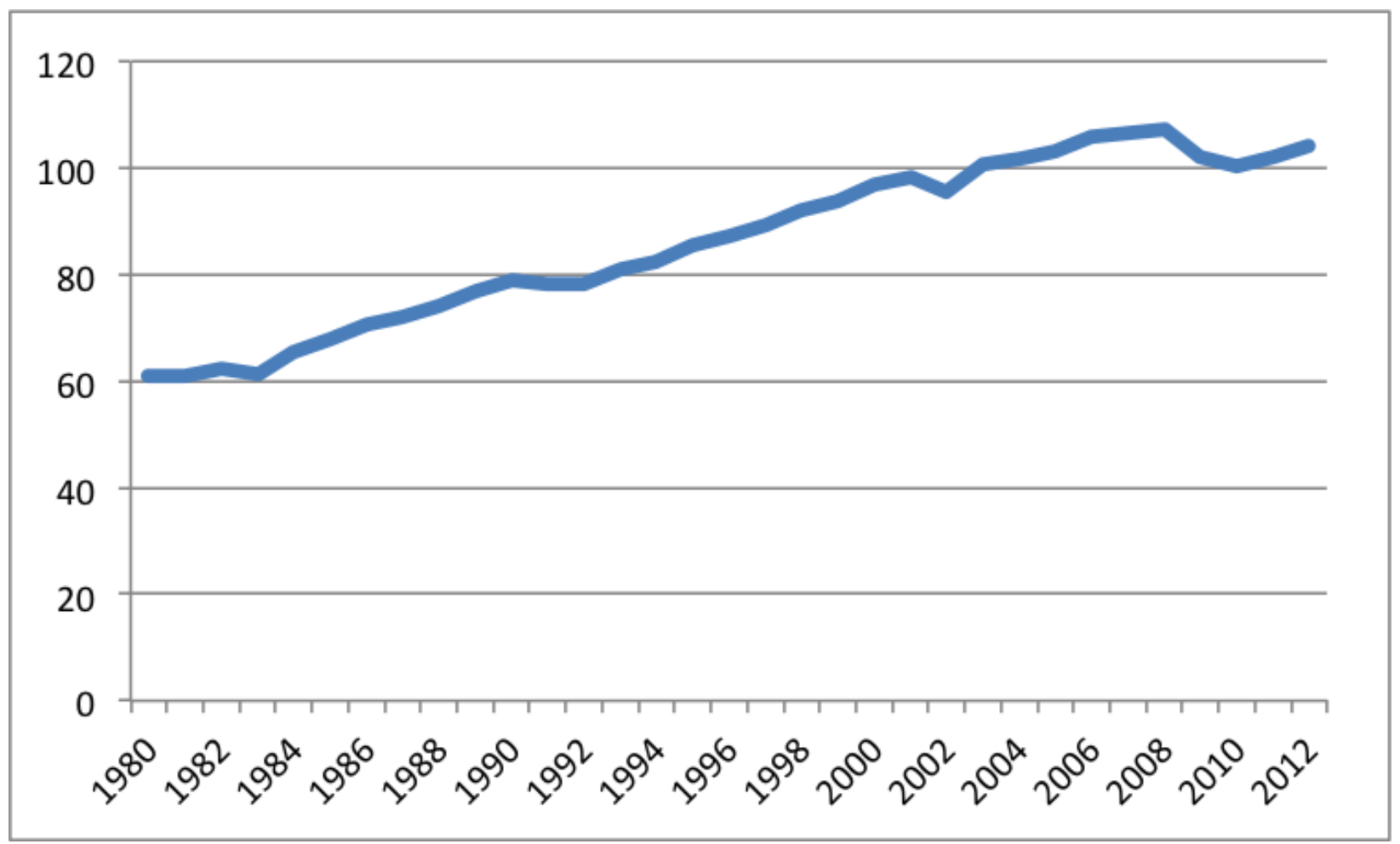


Figure 2: Employment-weighted average labor market concentration since 1980

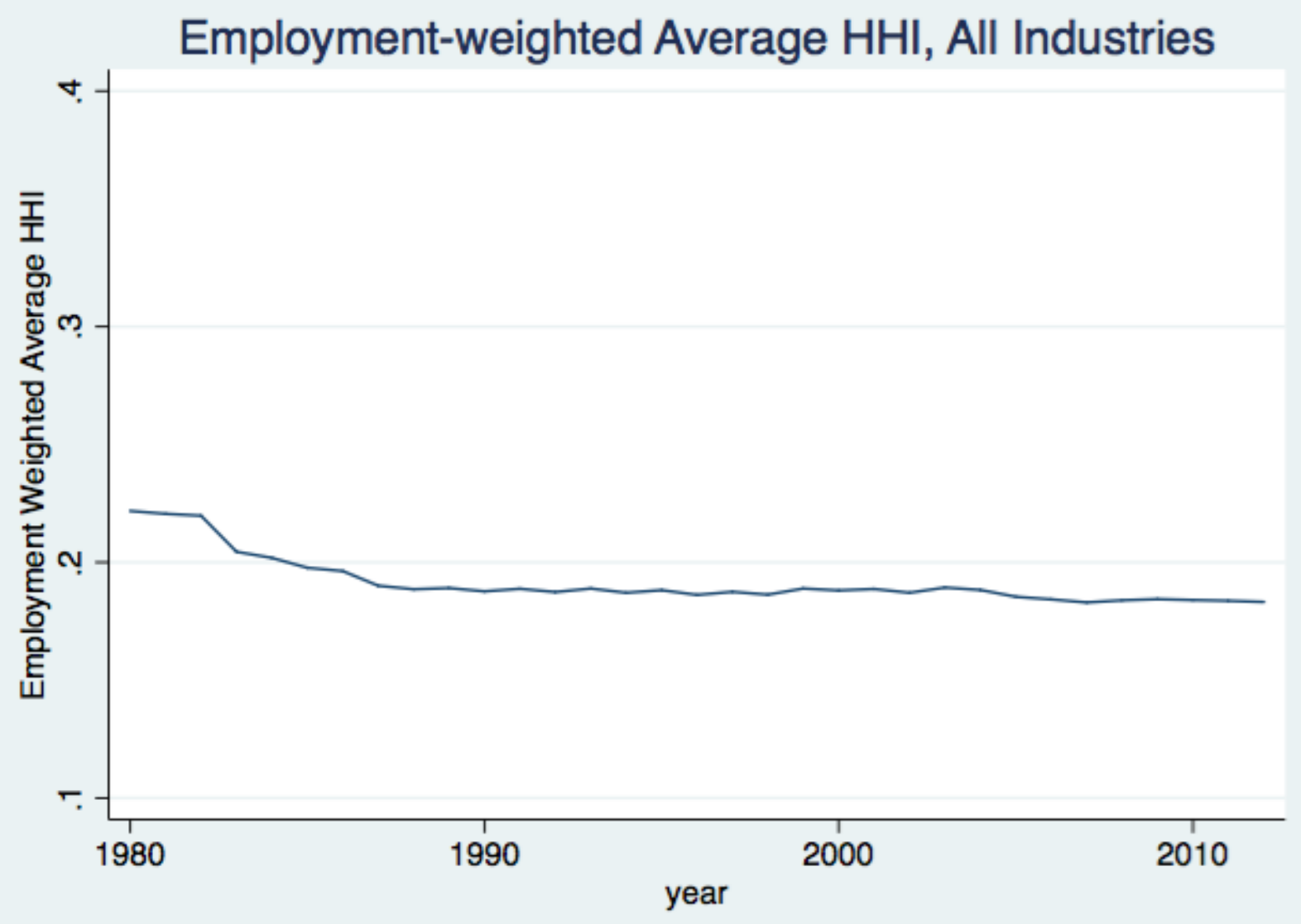


Figure 3: Change labor share due to changes in employment weighted average labor market concentration using estimated coefficients

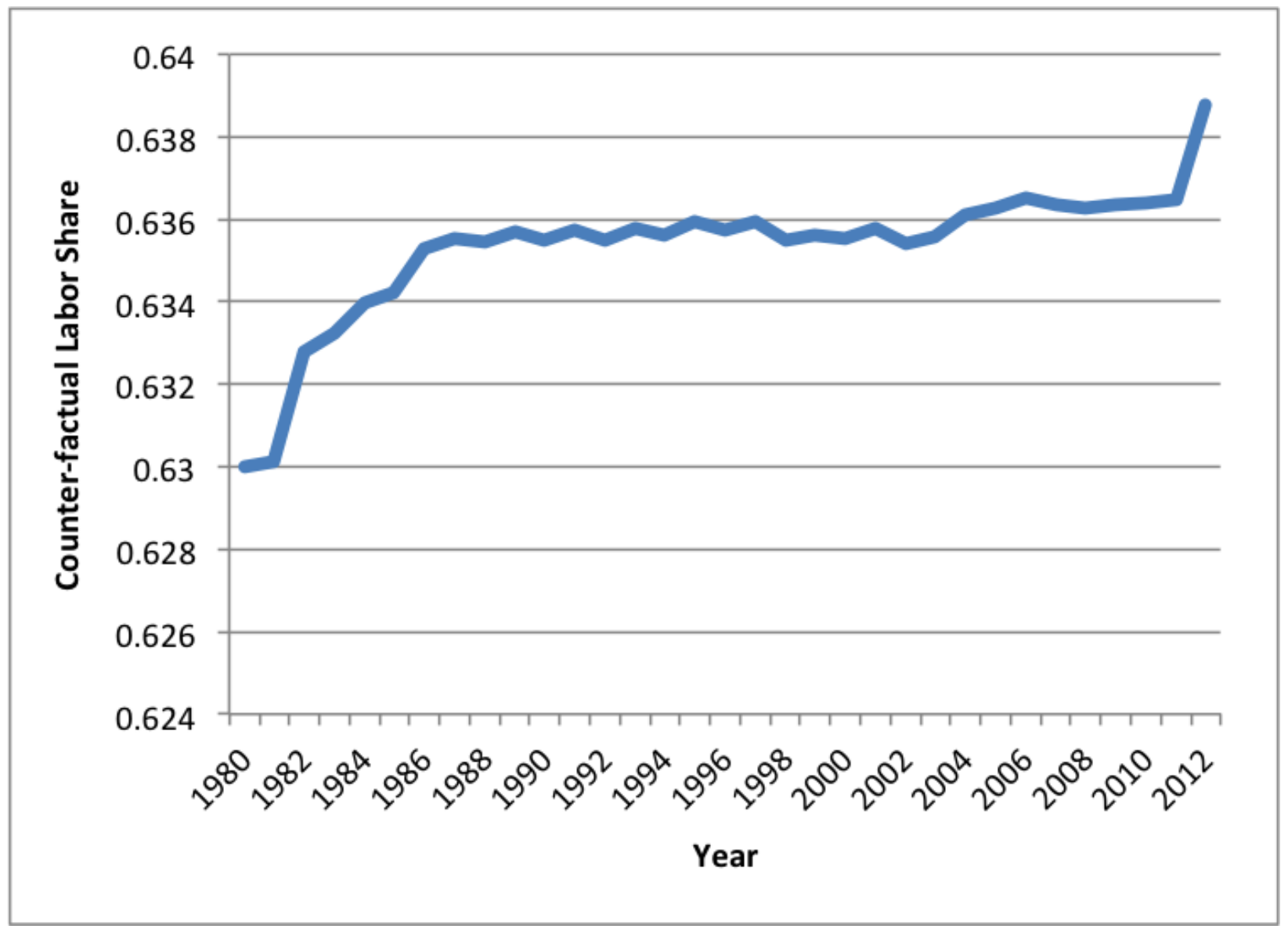


Figure 4: Employment-weighted average labor market concnetration since 1980 by industry
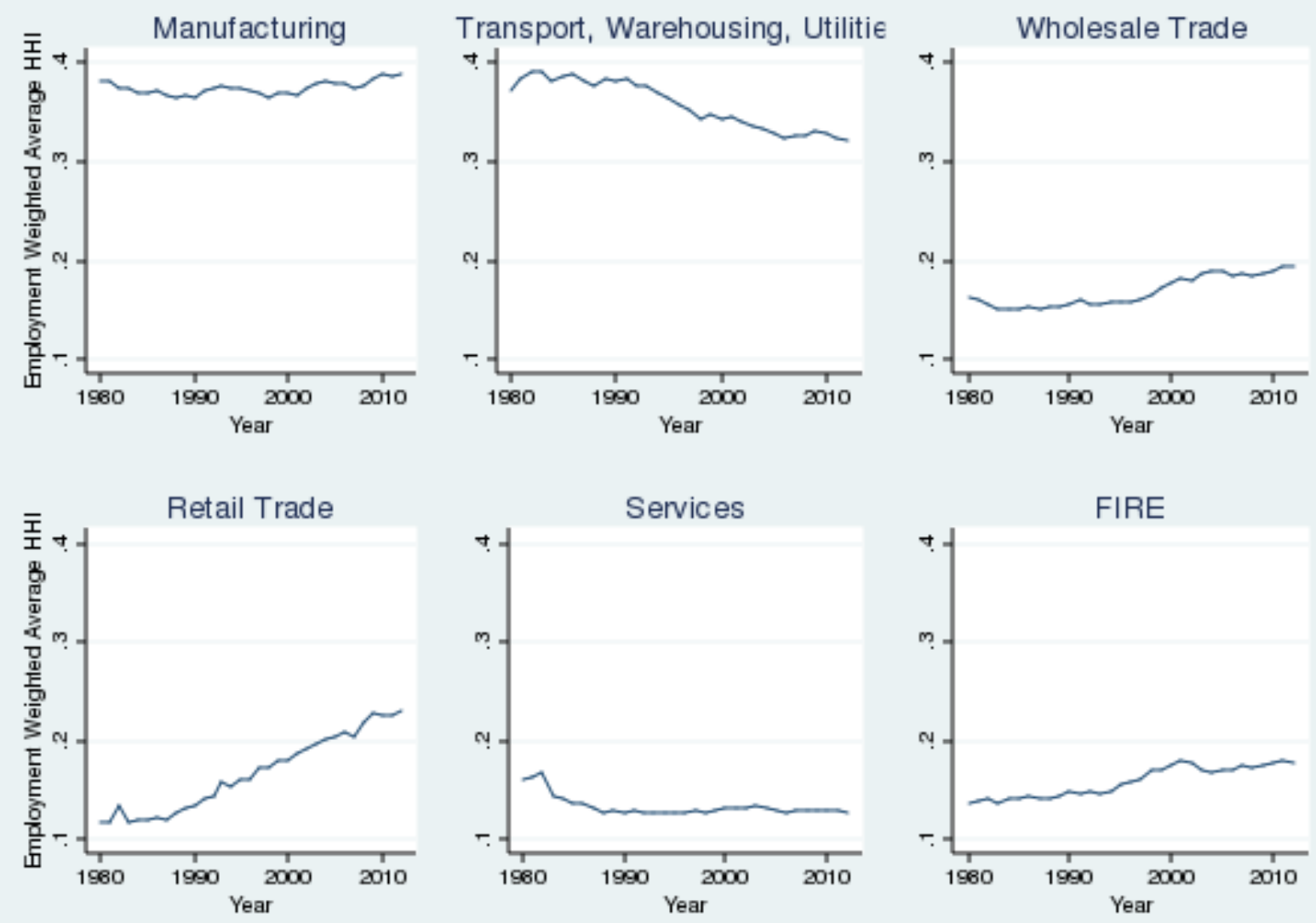
Figure 5: Average labor market concentration since 1980 calculated within labor markets

\section{Average $\mathrm{HHI}$, All Industries}

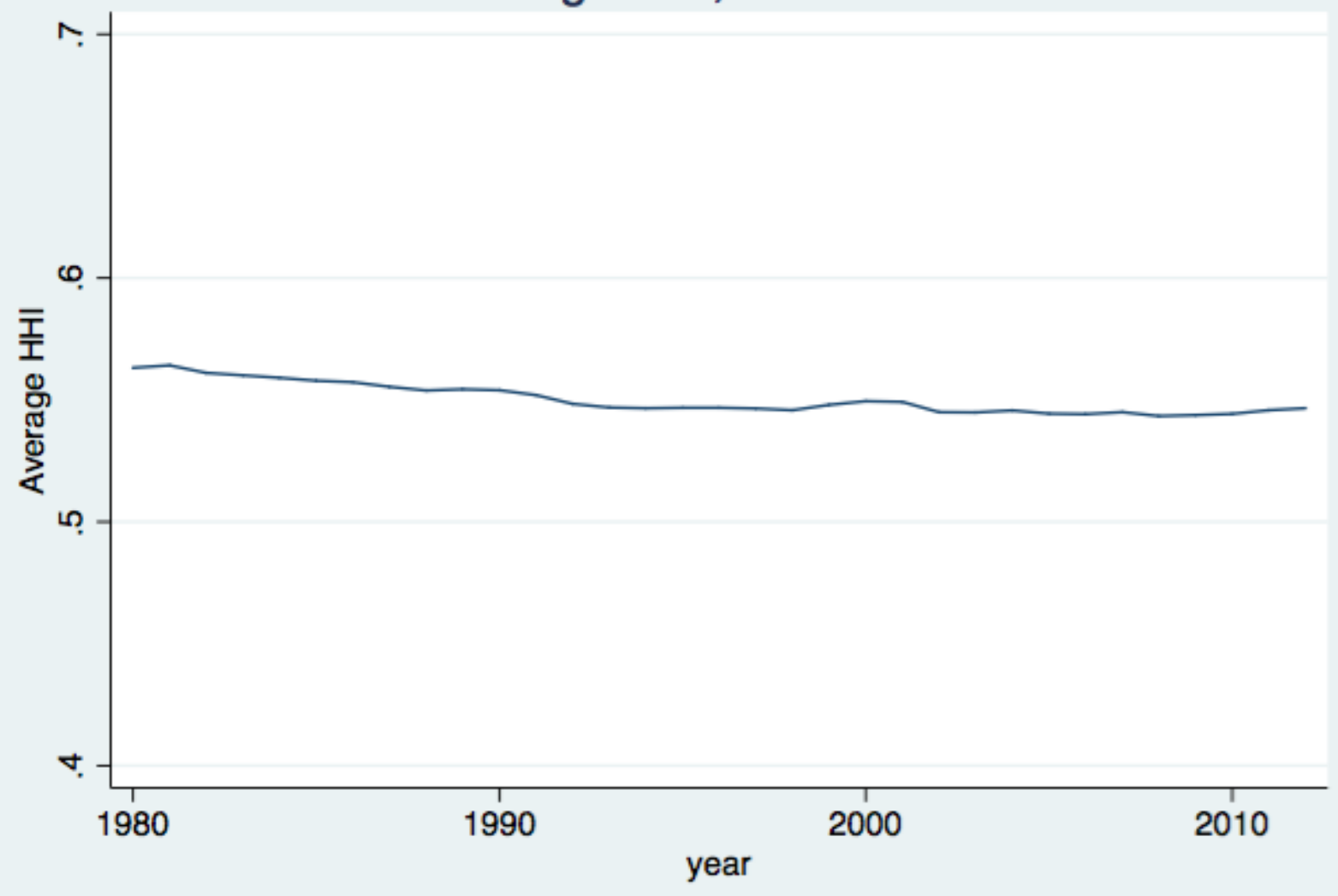


Figure 6: Average labor market concentration since 1980 by industry, NAICS 5
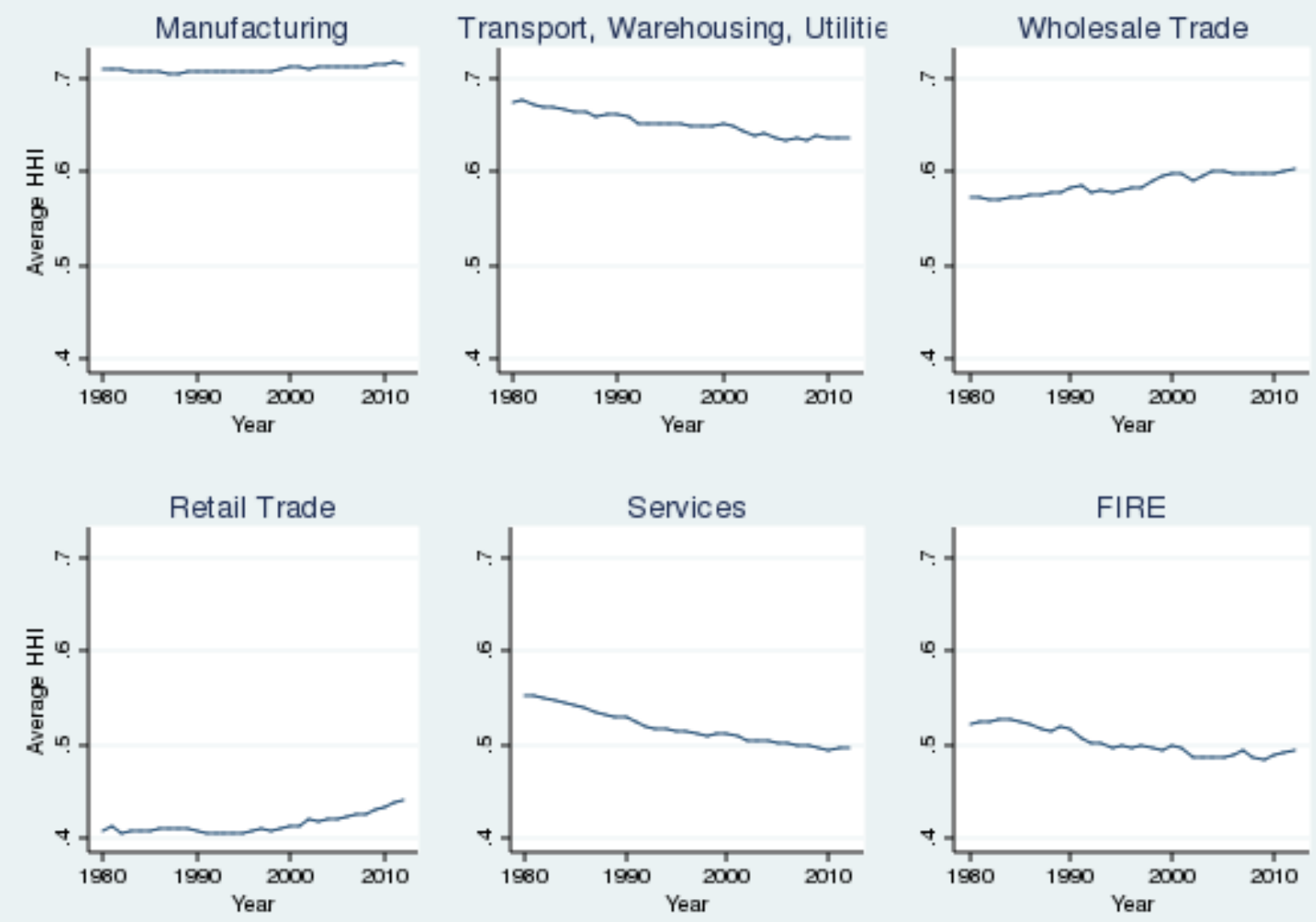
Figure 7: The marginal effect of labor market concentration on wages through time

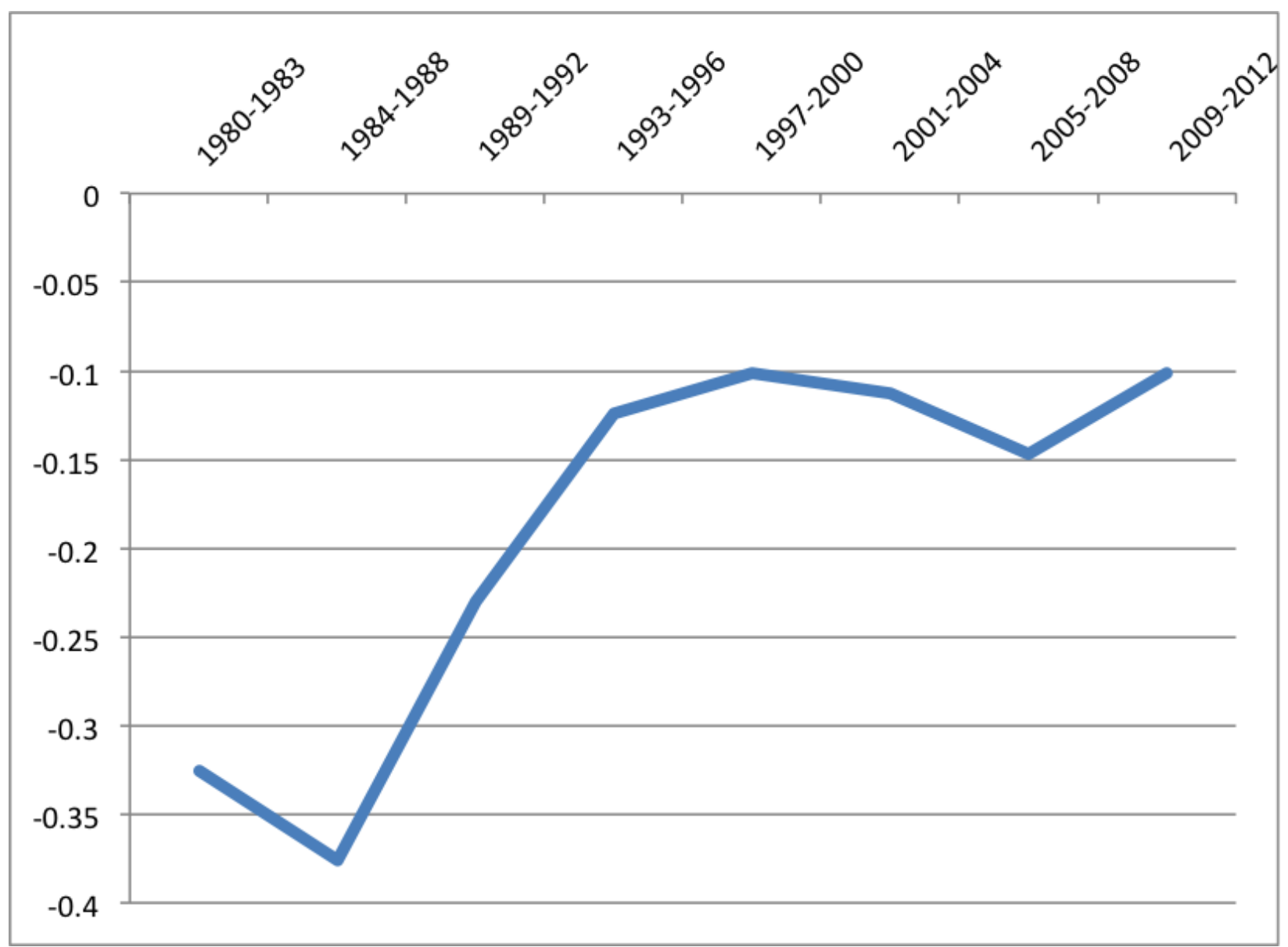

